\title{
PPTTG PENERAPAN MESIN PENGUPAS BAWANG MERAH DI DESA SUMBERJO KECAMATAN GONDANG KABUPATEN NGANJUK
}

\section{Ppttg The Application Of The Bawang Red Light Machine In Sumberjo Village, Gondang District, Nganjuk District}

\author{
Nila Nurlina ${ }^{1)}$, Ahmad Dony Mutiara Bahtiar ${ }^{2)}$, Rahayu Mekar Bisono ${ }^{3)}$ \\ 1,2,3 Program Studi Teknik Mesin, PSDKU Politeknik Negeri Malang Kota Kediri \\ Email: nila24.ppm@gmail.com ${ }^{1)}$
}

\begin{abstract}
ABSTRAK
Bawang merah merupakan salah satu produk unggulan masyarakat Nganjuk. Bawang merah merupakan bumbu dapur yang wajib ada pada setiap masakan. Bawang merah merupakan produk unggulan Desa Sumberjo, Kecamatan Gondang, Kabupaten Nganjuk dikarenakan lahan pertanian yang subur, serta bawang merah merupakan bumbu masak utama masyarakat Indonesia. Desa Sumberjo memiliki lima kelompok tani, tiga diantaranya merupakan mitra dalam PPTTG ini yaitu kelompok tani Sumber Rejeki, Sumber Makmur, dan Tunas Tani. Kelompok tani kreatif ini bertugas memberikan contoh dan mengayomi petani Desa Sumberjo agar dapat terus meningkatkan pendapatan dan mengelola hasil pertaniannya. Permasalahan yang dihadapi kelompok tani tersebut adalah tidak adanya inovasi produk akhir dalam rangka antisipasi harga jual yang anjlok dan hasil pertanian bawang merah yang tidak bagus, kurangnya pengetahuan dan ketrampilan kelompok tani dalam penerapan teknologi tepat guna. Dalam program pengabdian kepada masyarakat ini menghasilkan mesin pengolah bawang merah, salah satunya dibahas dalam makalah ini adalah mesin pengupas bawang merah. Kapasitas mesin sebesar $5 \mathrm{~kg}$ dengan waktu pengupasan 5 menit. Selain diberikan mesin, kelompok tani juga diberikan workshop mengenai pengelolaan usaha, perawatan mesin, dan pendampingan operasional pengoperasian mesin.
\end{abstract}

Kata kunci: Bawang merah, Kelompok tani, Pengupas.

\begin{abstract}
Red onion is one of the featured product in Nganjuk. Red onion are a spice that most be present in every food. Red onion is a superior product of Sumberjo Village, Gondang District, Nganjuk Regency because of its fertile agricultural land, and red onion are the main cooking spices of Indonesian people. Sumberjo village has five farmer groups, three of which are partners in the PPTTG, namely Sumber Rejeki, Sumber Makmur, and Tunas Tani farmer groups. This creative farmer group is tasked with setting an example and protecting the farmers of Sumberjo Village so that they can continue to increase their income and manage their agricultural products. The problems faced by the farmer groups are the absence of final product innovations in the context of anticipating a plummeting selling price and poor yield of red onion, low knowledge and skills of the farmer groups in the application of appropriate technology. In this public service program it produces an onion processing machine, one of which is discussed in this paper is the onion peeler machine. The capacity of the machine is $5 \mathrm{~kg}$ with a stripping time of 5 minutes. In addition to being given machinery, the farmer group was also given a workshop on business management, machine maintenance, and operational assistance for operating the machine..
\end{abstract}

Keywords: Farmer group, Peeler, Red onion. 


\section{PENDAHULUAN}

Bawang merah merupakan produk unggulan Desa Sumberjo, Kecamatan Gondang, Kabupaten Nganjuk dikarenakan lahan pertanian yang subur, sumber air melimpah, serta bawang merah merupakan bumbu masak utama masyarakat Indonesia. Desa Sumberjo merupakan daerah penghasil Bawang Merah dengan luas total area desa 415,79 Ha. Lebih dari separuh luas tanah yang dimiliki merupakan lahan persawahan dengan luas 273,50 Ha. Mayoritas pekerjaan penduduk Sumberjo ini adalah Petani dengan rata-rata lulusan SD

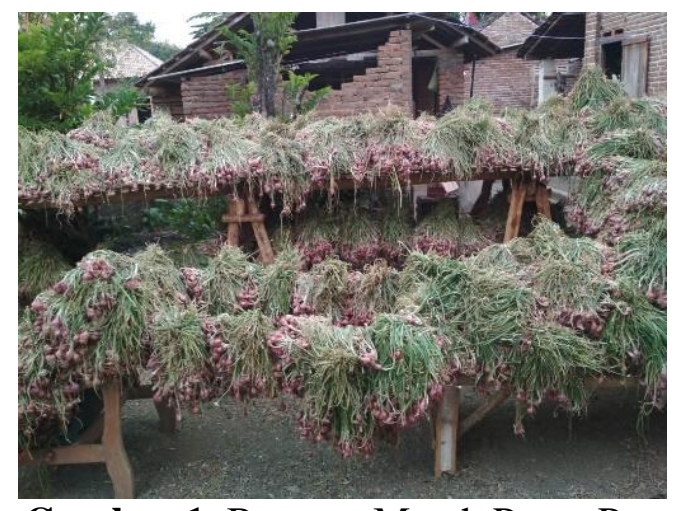

Gambar 1. Bawang Merah Pasca Panen

Mitra dalam PPTTG ini yaitu kelompok tani Sumber Rejeki, Sumber Makmur, dan Tunas Tani. Kelompok tani kreatif ini bertugas untuk memberikan contoh dan mengayomi petani Desa Sumberjo agar dapat terus meningkatkan pendapatan dan mengelola hasil pertaniannya. Aktivitas kelompok tani ini adalah saling bertukar pendapat mengenai langkah-langkah strategis dalam upaya meningkatkan produktivitas hasil pertanian bawang merah.

Ketiga kelompok tani yang dijadikan mitra dalam PPTTG ini biasanya menjual langsung hasil panen bawang merah kepada tengkulak yang mendatangi lokasi dengan metode tebasan maupun umbi. Bawang merah yang dijual tebasan tidak memerlukan penanganan lebih lanjut karena hasil panen dari sawah langsung dibawa oleh tengkulak tanpa melalui proses pemotongan daun dan penimbangan. Biaya yang diperlukan untuk proses penanganan hasil panen tebasan ini antara lain biaya tenaga kerja pemanen bawang sekitar 25 orang/bahu. Sementara, apabila dijual dalam bentuk umbi, biaya yang diperlukan adalah biaya tenaga kerja pemanen dan pemotong daun bawang merah.

Hasil panen bawang merah mitra ini belum pernah diinovasikan menjadi produk yang memberikan nilai jual tinggi dan stabil seperti bawang goreng. Pengolahan produk menjadi bawang goreng ini dapat mengatasi masalah ukuran umbi karena bawang goreng tidak tergantung pada besar kecilnya umbi. Berdasarkan referensi yang didapatkan dari situs online, harga jual bawang goreng ratarata $\operatorname{Rp~150.0000/kilo~gram.~}$

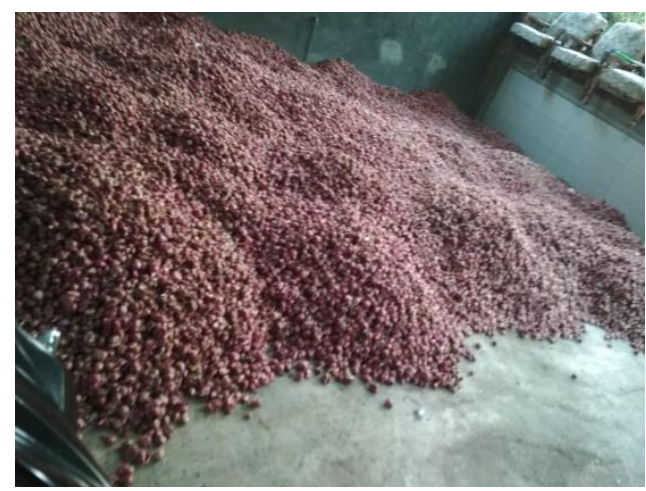

Gambar 2. Bawang Merah Siap Produksi

Oleh karena itu diperlukan penyelesaian permasalah tentang proses pengupas dan perajang bawang merah sehingga proses pembuatannya dapat lebih cepat dengan hasil yang lebih baik dibandingkan dengan cara manual. Oleh karena itu, dalam pengabdian masyarakat ini bertujuan untuk memberikan pelatihan kepada masyarakat untuk menggunakan teknologi tepat guna dalam mengolah hasil panen bawang merah dengan mesin pengupas bawang merah.

\section{SOLUSI DAN TARGET LUARAN}

Solusi yang ditawarkan untuk menghadapi permasalahan yang telah 
diuraikan pada latar belakang di atas adalah membuat mesin pengupas bawang merah. Desain mesin pengupas bawang merah ini mempertimbangkan aspek manfaat dan fungsi yang ingin dicapai. Alat pengupas bawang mekanis adalah alat yang dirancang untuk mengupas bawang dengan menggunakan tenaga penggerak motor listrik. Berikut merupakan desain gambar mesin tepat guna yang akan digunakan dalam kegiatan pengabdian masyarakat.

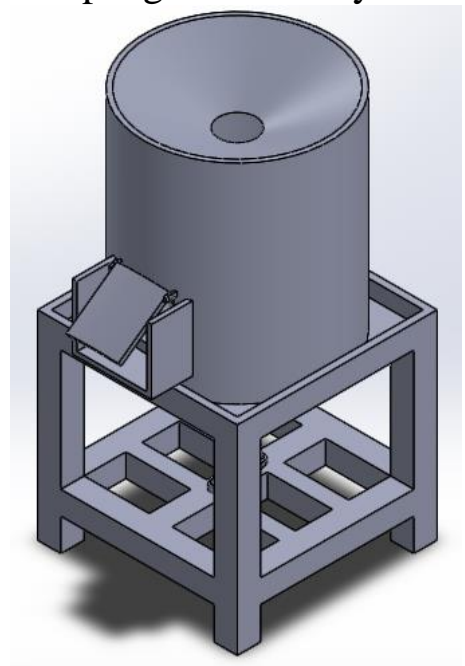

Gambar 3. Desain Mesin Pengupas Bawang Merah (Tampak Samping)

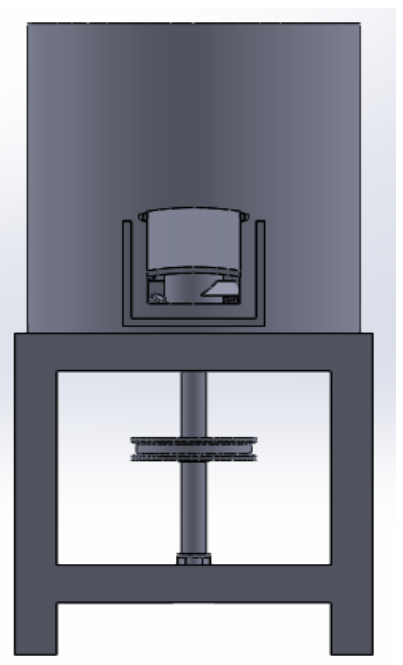

Gambar 4. Desain Mesin Pengupas Bawang Merah (Tampak Depan)
Adapun bagian-bagian utama pada mesin pengupas kulit bawang semi otomastis yaitu:

\section{Sistem transmisi}

Sistem transmisi digunakan untuk meneruskan tenaga dari motor listrik menuju pengupas. System transmisi yang digunakan adalah $\mathrm{v}$ belt yang dihubungkan dengan pulley.

2. Bagian Pengupas

Bagian ini yang digunakan untuk mengupas kulit bawang yang sudah melalui tahap pemotongan atau pemisahan daun dan umbi bawang merah.

\section{Luaran dan Target Capaian}

Target luaran yang dihasilkan dalam program pengabdian ini yaitu :

1. Mesin pengolah bawang merah terintegrasi terdiri dari proses pemotongan daun, pengupas, dan perajang bawang merah.

2. Pelatihan pengoperasian mesin dan perawatan mesin.

\section{METODE PELAKSANAAN KEGIATAN}

Kegiatan Pengabdian Masyarakat skema Program Penerapan Teknologi Tepat Guna (PPTTG) ini dilaksanakan di Desa Sumberjo Kecamatan Gondang, Kabupaten Nganjuk, Jawa Timur. Progam ini dihadiri oleh tiga mitra kelompok tani Desa Sumberjo. Pelaksanaan program pengabdian ini melalui dua tahap yaitu pemberian materi dan praktik operasional penggunaan mesin pengupas bawang merah beserta cara merawatnya.

Kegiatan pelatihan merupakan kegiatan untuk memberikan pelatihan penggunaan operasional alat. Selain itu, dalam kegiatan ini juga mengundang beberapa narasumber untuk menyampaikan workshop mengenai cara manajemen usaha.

Praktik operasional penggunaan mesin dilakukan setelah proses serah terima mesin. Pada kegiatan ini kelompok tani Desa Sumberjo diberikan bekal pengetahuan 
mengenai prosedur menggunakan mesin dengan baik dan benar. Selain itu pada kegiatan ini juga diberikan pelatihan mengenai cara merawat mesin.

Langkah-langkah pembuatan sistem pemotong daun bawang dan pengupas bawang merah sebagai berikut:

1. Pembuatan bagian wadah pisau

2. Pembuatan casing dan tabung pengupas

3. Pembuatan poros, pasak, dan bantalan

4. Pembuatan rangka

5. Pengaturan sistem transmisi

6. Pemasangan instalasi motor listrik

Langkah-langkah perencanaan elemen mesin sistem pengupas berdasarkan studi literatur yang telah dilaksanakan, maka dilanjutkan dengan perencanaan elemen mesin pada sistem pengupas sebagai berikut:

\section{Perencanaan Daya}

Pada perencanaan daya untuk sistem pengupas akan direncanakan torsi yang dibutuhkan untuk sistem pengupas dengan kapasitas pengupasan sampai $5 \mathrm{~kg}$ agar dapat menghitung daya motor yang diperlukan untuk menjadi penggerak pada sistem pengupas.

\section{Perencanaan Sistem Pengupas}

Pada perencanaan sistem pengupas akan direncanakan kapasitas bawang yang akan dikupas dan efisiensi hasil pengupasan agar sampai $80 \%$.

\section{Perencanaan Poros}

Pada perencanaan poros pengupas menggunakan perencanaan poros dengan beban puntir dan lentur. Poros pada pengupas akan meneruskan daya melalui sabuk dan puli. Dengan demikian poros tersebut mendapat beban puntir dan lentur sehingga pada permukaan poros akan terjadi tegangan geser karena momen puntir dan tegangan lentur. Dengan demikian dihasilkan pemilihan poros pada pengupas dengan perhitungan torsi dan daya yang ditransmisikan dengan beban pengupas sebesar $5 \mathrm{~kg}$.

\section{Perencanaan Bantalan}

Pada perencanaan bantalan yang akan digunakan adalah bantalan gelinding keunggulan bantalan ini adalah pada gesekannya yang sangat rendah dan pelumasannya sangat sederhana. Dengan demikian bantalan yang digunakan adalah bantalan gelinding dengan beban radial dan nomor bantalan 6010, kapasitas nominal dinamis spesifik $1710(\mathrm{~kg})$ dan nominal statis spesifik 1430 $(\mathrm{kg})$, panjang bantalan $16 \mathrm{~mm}$.

Dari data diatas akan dihasilkan kapasitas dan kecepatan sistem pengupas yang sesuai dengan perhitungan dan menghasilkan pengupasan yang baik.

\section{HASIL DAN PEMBAHASAN}

Kegiatan pengabdian kepada masyarakat skema Penerapan Teknologi Tepat Guna di desa Sumberjo bertujuan untuk meningkatkan pendapatan masyarakat pasca panen bawang merah. Mitra kegiatan pengabdian masyarakat ini adalah tiga kelompok tani di Desa Sumberjo yaitu kelompok tani Sumber Makmur, kelompok tani Sumber Rejeki, dan kelompok tani Tunas Tani.

Kegiatan pengabdian masyarakat ini menghasilkan satu paket mesin pengolah bawang merah yang salah satunya berfungsi untuk mengupas kulit bawang merah.

Pada proses perakitan sistem pengupas alat-alat yang digunakan sebagai berikut:

1. Penggores

2. Roll

3. Penggaris meteran

4. Gerinda

5. Palu

6. Bor

7. Tang jepit

8. Tembakan paku rivet 


\section{Las SMAW}

\subsection{Langkah-langkah Perakitan Sistem Pengupas}

Berikut langkah-langkah dalam pengerjaan dan perakitan sistem pengupas Rancang Bangun Sistem Pengupas Mesin Pengupas Bawang Merah MPB VIII sebagai berikut:

1. Pengerjaan poros pengupas

2. Proses pengeboran

3. Pembuatan casing pengupas

4. Pembuatan tabung pengupas

5. Pengelasan pada sistem pengupas

6. Pengelasan dudukan pengupas pada rangka

7. Proses penyetelan v-belt pada bagian transimisi dan sumber daya

8. Pemasangan casing pengupas

9. Pemasangan tabung pengupas

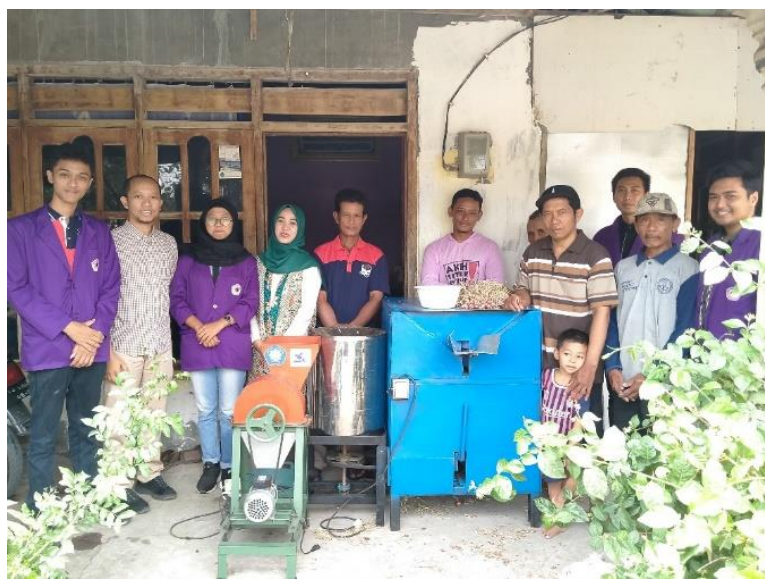

Gambar 5. Kegiatan Uji Coba Alat dan Pendampingan Operasional Alat

Proses pengupasan bawang merah menggunakan mesin yang telah dibuat oleh tim pengabdian dapat dilihat sebagai berikut.

\section{Proses pemotongan daun bawang merah}

Pada proses ini dilakukan pemisahan antara daun dengan umbi bawang merah. Proses ini bias dilakukan secara manual maupun dengan menggunakan mesin yang telah dirancang oleh tim pengabdian.
Berikut merupakan hasil pemotongan daun bawang merah dengan umbiya.

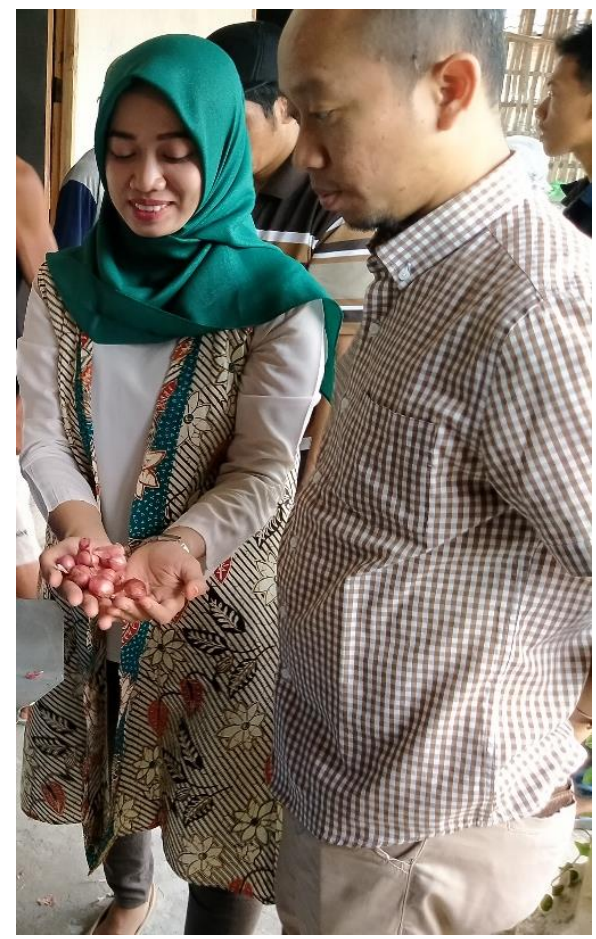

Gambar 6. Hasil Pemotongan Daun Bawang Merah dengan Mesin

\section{Proses Pengupasan}

Proses pengupasan dilakukan dengan mesin yang telah dirancang oleh tim pengabdian ini. Proses pengupasan dapat dilakukan dengan waktu yang sangat singkat. Kapasistas mesin pengupas yang telah dirancang mencapai $5 \mathrm{~kg}$ untuk menghasilkan hasil kupasan bawang merah yang sempurna. Namun, tidak menutup kemungkinan bahwa mesin yang telah dirancang mampu menampung $10 \mathrm{~kg}$ bawang merah. Setiap $5 \mathrm{~kg}$ bawang merah membutuhkan waktu pengupasan sekitar 5 menit. Proses pengupasan sangat sederhana, dimana kelompok tani hanya menyiapkan bawang merah yang sudah dipotong daunnya, lalu dimasukkan ke dalam tabung pengupas. Berikan air ke dalam tabung pengupas selama proses pengupasan berlangsung. 


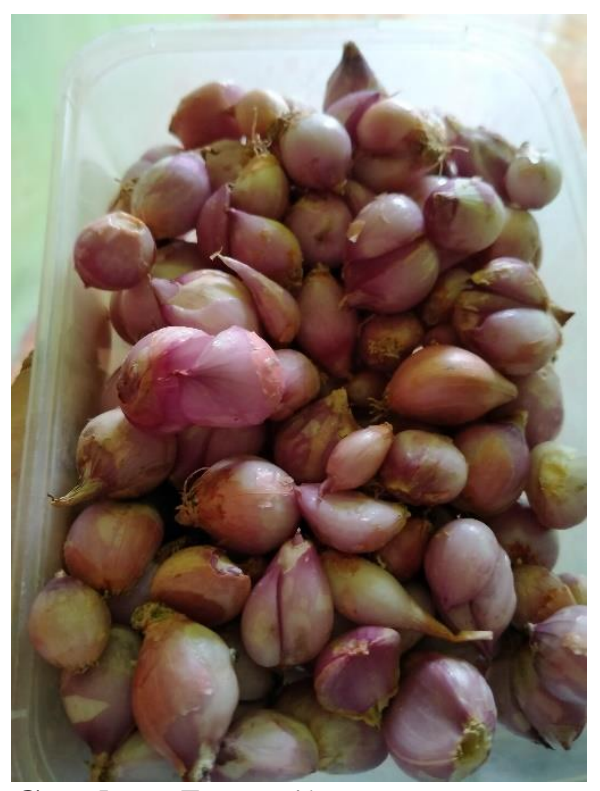

Gambar 7. Hasil Pengupas Bawang Merah dengan Mesin Pengupas

\section{KESIMPULAN DAN SARAN}

Program Pengabdian Masyarakat ini dilakukan di Desa Sumberjo, Kabupaten Nganjuk, Jawa Timur. Kegiatan Pengabdian Kepada Masyarakat ini menghasilkan Teknologi Tepat Guna berupa Mesin pengupas bawang merah. Selain menghasilkan mesin, pengabdian ini juga menghasilkan workshop bagi kelompok tani Desa Sumberjo, Kabupaten Nganjuk, Jawa Timur.

\section{UCAPAN TERIMA KASIH}

Ucapan terima kasih saya sampaikan kepada Direktorat Jendral Penelitian dan Pengabdian Masyarakat Kementerian Ristek Dikdi yang telah memberikan bantuan dana hibah Program Penerapan Teknologi Tepat Guna Tahun anggaran 2019 sehingga kegiatan ini dapat terlaksana dengan baik.

\section{DAFTAR PUSTAKA}

H. Husniah, H. A. Maulana, U. S. Pasaribu and B. P. Iskandar, "Two-dimensional Lease Contract with Preventive Maintenance using Bivariate Weibull," International Journal of Industrial Engineering, vol. 26, no. 1, pp. 48-58, 2019.

H. Pinto, C. Pimentel and M. Cunha, "Implications of Total Productive Maintenance in Psychological Sense of Ownership," Social and Behavioral Sciences, vol. 217, p. 1076 - 1082, 2016.

K. Matyas, T. Nemeth, K. Kovacs and R. Glawar, "A Procedural Approach for Realizing Prescriptive Maintenance Planning in Manufacturing Industries," CIRP Annals - Manufacturing Technology, pp. 1-4, 2017.

K. Murata and H. Katayama, "Development of Kaizen Case-base for Effective Technology Transfer - A Case of Visual Management Technology," International Journal of Production Research, vol. 48, no. 16, pp. 4901-4917, 2010. M. Lewandowski and S. Oelker, "Towards Autonomous Control in Maintenance and Spare Part Logistics - Challenges and Opportunities for Preacting Maintenance Concepts," Procedia Technology, vol. 15, pp. 333-340, 2014.

K. Pertanian, Outlook Bawang Merah, Jakarta: Pusat Data dan Sistem Informasi Pertanian Kementerian Pertanian, 2016.

S. Hashim, F. N. Habidin, J. Conding, A. F. Zubir and N. A. Jaya, "The Integrated Between Total Production Maintenance Practices and Kaizen Event Practices In Malaysian Automotive Industry," International Journal of Engineering Research and Applications, vol. 2, no. 5, pp. 136-143, 2012. 